\title{
JERÓNIMO SÁNCHEZ COELLO: UN DISCÍPULO DE TIZIANO EN SEVILLA
}

\author{
Lina Malo Lara y Antonio Joaquín Santos Márquez \\ Universidad de Sevilla
}

\begin{abstract}
Presentamos en este artículo noticias inéditas sobre la vida y la obra del pintor Jerónimo Sánchez Coello, hermano del afamado pintor de cámara del rey Felipe II, Alonso, durante su estancia en Sevilla a finales del siglo XVI, tras su formación en el taller de Tiziano.
\end{abstract}

Palabras clave: Jerónimo Sánchez Coello; Tiziano; Pintura; Siglo XVI; Sevilla.

\section{JERÓNIMO SÁNCHEZ COELLO: A DISCIPLE OF TITIAN IN SEVILLE}

In this paper the authors present unpublished documents relating to the life and work of the painter Jerónimo Sánchez Coello, brother of the famous court painter to Philip II, Alonso, during his residence in Seville toward the end of the $16^{\text {th }}$ century, following his artistic training in Titian's workshop.

Key words: Jerónimo Sánchez Coello; Titian; Painting; $16^{\text {th }}$ century; Seville.

Jerónimo Sánchez Coello pertenece a la generación de pintores foráneos que se establecieron en Sevilla durante el último tercio del siglo XVI, al abrigo de la prosperidad americana. La capital andaluza se convirtió entonces en uno de los centros más ricos y atractivos para artistas venidos desde diversos puntos de España y del extranjero. A diferencia de lo que sucede con buena parte de estos creadores, el pintor que protagoniza nuestro estudio es todavía bastante desconocido. La causa se debe, esencialmente, a que parte de su vida estuvo a la sombra de su hermano, el afamado Alonso Sánchez Coello, y a que, cuando definitivamente se emancipó, tras su traslado a Sevilla, de su producción pictórica nada nos ha llegado que revalide la valía artística que le adjudicaron sus contemporáneos. Así lo revelan las fuentes escritas, que nos muestran a un artista formado en el taller veneciano de Tiziano, cumbre del arte de la pintura de su tiempo.

Sobre Jerónimo, a día de hoy, es poco lo que se ha escrito. Ya en su estudio sobre la presencia de Tiziano en la España del Siglo de Oro, Pérez Sánchez incluyó al pintor entre los discípulos del veneciano, apuntando la inexistencia de obras del artista y la suposición de que moriría joven, debido a la casi total ausencia de noticias sobre el mismo ${ }^{1}$. Nuevas referencias documen-

\footnotetext{
1 PÉrez SÁnChez, 1976: 148-149.
} 
tales sirvieron de guía para el trabajo monográfico de Rosemarie Mulcahy², quien estudió su relación con Alonso y la Corte, sus años en Venecia y sus inicios como pintor en Madrid, apuntando los pocos datos que se conocían de su estancia en Sevilla. La frustrante ausencia de obras de su mano y el silencio de la documentación hicieron pensar a Mulcahy que su carrera, a pesar de todas las ventajas que obtuvo, fue un fracaso; quizás, por haberse dedicado a otras actividades, o debido también a su conocida condición de hábil pero, acaso, simple copista, circunstancia que habría hecho que su trabajo pasara desapercibido a la posterioridad, escondido entre las obras atribuidas al taller de su hermano ${ }^{3}$. Tras el descubrimiento ahora de importantes noticias sobre su quehacer artístico durante su estancia en la capital andaluza, podemos cuestionar aquí esta suposición.

Se cree que Jerónimo nació en Castelo Rodrigo (Portugal) poco después de 1540. Fue hijo de Luis Sánchez Galván y de su segunda esposa, Catalina Rodríguez, casados en dicho año; por lo tanto, era hermano sólo de padre de Alonso Sánchez Coello 4 . Junto a él se crió en tierras portuguesas, donde Alonso desarrollaría parte de su formación bajo la protección de la reina doña Juana. La familia al completo debió de trasladarse a Madrid cuando Alonso recibió su nombramiento como pintor de cámara, a principios de $1560^{5}$. El ya pintor del rey, con quién Jerónimo hubo de iniciar su formación, deseoso de que completase su aprendizaje, consiguió el favor de Felipe II para que lo trasladara, en 1574, al taller de Tiziano (c. 1489-1576). Aunque esta circunstancia delata el interés que pudieron despertar las habilidades artísticas de Jerónimo, hemos de recordar la frecuente solicitud de ayuda para sus familiares que Alonso cursó ante Felipe II; igualmente, los intereses del propio monarca: mediante Jerónimo, comprobar qué había aún en el obrador del veneciano que le pudiera interesar y apremiar al ya anciano maestro en sus encargos $^{6}$. Entre éstos, se encontraba la obra Felipe II, después de la victoria de Lepanto, ofrece al cielo al príncipe don Fernando (Museo del Prado) (fig. 1), cuya realización encomendó a Tiziano sobre un modelo de Alonso Sánchez Coello. Tal como ha sido advertido, el maestro no debió sentirse cómodo con este encargo, pues delegó parte de su realización en sus ayudantes ${ }^{7}$. Que Jerónimo, quien remitió a la Corte española esta pintura, hubiera podido intervenir en ella es una hipótesis, aunque no sería extraño, dada su proximidad al autor del modelo de la obra. Sí se sabe que, en dicho envío, incluyó la copia que hizo del célebre lienzo de Tiziano La Muerte de San Pedro Mártir, original sobre el que se hicieron numerosas copias y grabados (fig. 2). La obra de Jerónimo, hoy perdida, fue muy alabada por el embajador español en Venecia y daría cuenta de un notable esfuerzo por su parte. Debió enviarla a la Corte muy posiblemente para conseguir el favor del rey ${ }^{8}$. En Venecia, donde trabajaría también como agente al servicio de Felipe II para la adquisición de pigmentos, comenzó a granjearse una clientela entre la nobleza española, que admiraba su faceta como copista de las obras venecianas más renombradas 9 .

Tras su formación en Italia, Jerónimo regresó a Madrid en 1582. En 1584 se desposó con Antonia de Liaño ${ }^{10}$, emparentada con el miniaturista Felipe de Liaño, colaborador de Alonso

\footnotetext{
2 Mulcahy, 1990: 304-309.

3 También recogen al pintor Kusche, 2003: 381-384. Redin Micheus, 2007: 292-293.

4 Jerónimo debió asumir el apellido Coello, de ascendencia paterna, para evidenciar su parentesco con Alonso, dada la importancia que iba adquiriendo éste en los círculos cortesanos.

5 Cfr. Kusche, Ob. cit.: 64 y 381.

${ }^{6}$ Kusche, Ob. cit.: 382.

7 FALOMir Faus, 2003: 288; 2005: 153-158.

8 Mulcahy: Ob. cit.: 306, nota 7. Kusche: Ob. cit.: 383.

9 Mulcahy, Ob. cit.: 306-307.

${ }_{10} \mathrm{Si}$ tomamos por cierto que Jerónimo nació hacia 1540, tendría entonces unos 44 años. Esta edad nos resulta bastante avanzada para casarse, por lo que su nacimiento pudo producirse más tarde de lo supuesto.
}

Arch. esp. arte, LXXXVII, 345, ENERO-MARZO 2014, 15-28 ISSN: 0004-0428, eISSN: 1988-8511, doi: 10.3989/aearte.2014.02 


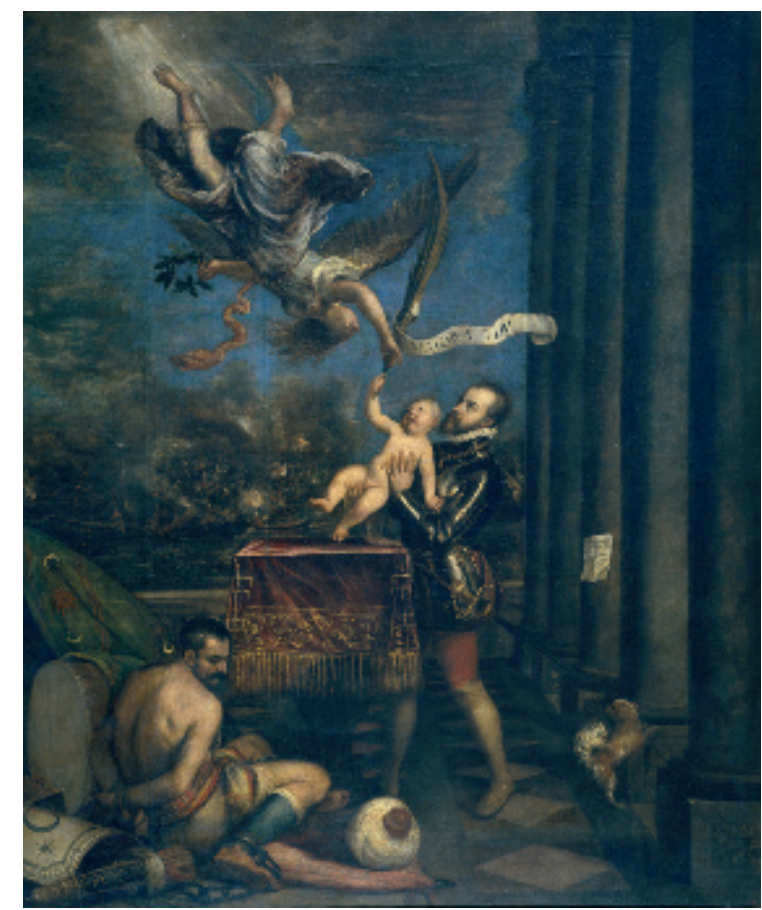

Fig. 1. Tiziano y taller. Felipe II, después de la victoria de Lepanto, ofrece al cielo al príncipe don Fernando. 1573-1575. Museo Nacional del Prado, Madrid.

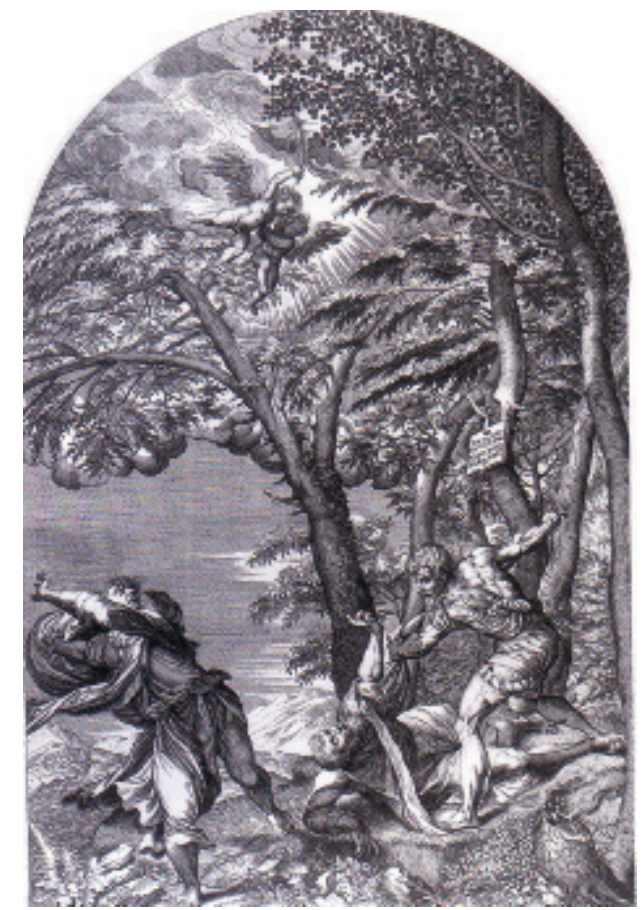

Fig. 2. Martino Rota sobre La muerte de San Pedro Mártir de Tiziano. H. 1568. Museo Británico, Londres.

Sánchez Coello, y posible pintora también ella ${ }^{11}$. En estos años, y a pesar de la omnipresencia de Alonso en la Corte, Jerónimo no consiguió ningún encargo artístico ni puesto relevante. En estas fechas los encargos reales recayeron en maestros como Juan Pantoja de la Cruz, sucesor de su hermano como pintor del rey, o en los italianos Urbino, Cincinato, Cambiaso o Zuccaro, quienes trabajarían en El Escorial. Quizás las expectativas del monarca sobre Jerónimo no se habían cumplido, o sus gustos caminaban hacia maneras más propias del manierismo romano, como parece evidenciarse de los pintores mencionados. Sea como fuere, lo cierto es que Jerónimo, al no ver colmadas sus aspiraciones, y al igual que muchos artistas del momento, vería en Sevilla una salida profesional esperanzadora.

Del artista nada se sabía hasta 1591, cuando se le documentaba en Sevilla. Ahora conocemos que su traslado a la capital andaluza tuvo que producirse entre 1584, año de su boda, y 1586, pues en este año lo encontramos residiendo en la collación sevillana de San Isidoro ${ }^{12}$. Pronto se integró en los círculos artísticos de la ciudad, relacionándose con importantes creadores y recibiendo el beneplácito de la alta sociedad sevillana, que tendrá como principal cliente. La primera prueba de ello es su aparición como fiador en el concierto de las mazas capitulares sevillanas, firmado en 1587 entre el platero Francisco de Valderrama y el asistente de la ciudad don Diego

11 Kusche: $O b$. cit.: 384. De la Torre FAZIO, 2009: 158-159.

12 El 9 de octubre se fecha una carta de pago otorgada por Jerónimo a don Alonso de Rueda Niño, por valor de doscientos cincuenta reales, sin que se especifique la naturaleza de dicho adeudo. Archivo Histórico Provincial De Sevilla. Sección De Protocolos Notariales De Sevilla. (En adelante AHPSe. SPNSe.) Legajo 4983, oficio 7, libro 2. ${ }^{\circ}$ de 1586, fol. 920 rto.-vto.

Arch. esp. arte, LXXXVII, 345, ENERO-MARZO 2014, 15-28

ISSN: 0004-0428, eISSN: 1988-8511, doi: 10.3989/aearte.2014.02 
Núñez Pérez ${ }^{13}$. Este documento nos permite también conocer su traslado a la collación de San Miguel, donde tenían sus obradores los principales pintores del momento.

El primer testimonio de un encargo artístico en el que participó Jerónimo en Sevilla lo tenemos poco después. El 11 de febrero de 1588 un pintor secundario, Juan Girón, concertó la pintura y dorado de la bóveda de una capilla del monasterio de Santa María de Jesús, propiedad de don Andrés Sáenz de Portillo ${ }^{14}$. Girón se comprometió a seguir el modelo ideado por Jerónimo para esta obra, utilizando para ello colores "finos" cuya calidad debía supervisar nuestro pintor. Se trata, a nuestro entender, de un reconocimiento del marchamo de calidad de su formación en Italia. Sin duda, su aprendizaje en Venecia y su trabajo como agente real para la adquisición de pigmentos, le hacían perfecto conocedor de las calidades de los colores. Desgraciadamente, en el documento no se especifican apenas datos sobre esta obra, que creemos perdida, aparte de los económicos ${ }^{15}$.

Al tiempo que Jerónimo se introducía en los círculos artísticos de la ciudad, comenzó a entablar contactos comerciales con tierras americanas, enviando joyas y, como comprobaremos más adelante, también pinturas. Documentos fechados en 1589 y 1590 revelan que remitió a las Indias joyas de ricos materiales ${ }^{16}$. Estos negocios serían una constante en sus años sevillanos, y una prueba de que sus actividades se diversificaban para obtener otras fuentes de ingresos aparte de las generadas por su arte.

Se suceden en 1590 diversos poderes y cartas de pago del artista relacionadas con deudas de motivos no especificados ${ }^{17}$. En 1591 se fecha un encargo artístico de relieve: junto al escultor Gaspar Núñez Delgado, firmó el contrato del retablo mayor de la desaparecida iglesia del monasterio sevillano de las Santas Justa y Rufina ${ }^{18}$. Su labor debía consistir en policromar, dorar y estofar el conjunto, incluidas las imágenes y relieves, así como pintar una serie de lienzos historiados. Este retablo, por razones que se ignoran -posiblemente pudo deberse al fallecimiento del pintor, al año siguiente según veremos-, no llegó a hacerse, pues en 1600 se encargó de nuevo a otros artífices ${ }^{19}$. No obstante, este concierto es interesante, entre otras razones, porque testimo-

13 SANTOS Márquez, 2009: 155-168.

14 AHPSe. SPNSe.: Legajo 1598, oficio 3. Libro 1. ${ }^{\circ}$ de 1588, fols. 123 rto.-124 rto. Del cliente se dice que era "pagador", denominación que, quizás, se refiera al cargo de Pagador de Armadas y Flotas de la Carrera de Indias.

15 Se concertó por ochocientos reales de plata. No se indica la ubicación de la capilla, que pensamos pudo encontrarse en las proximidades del claustro, en una zona donde se hallan capillas de la misma época, algunas de las cuales desaparecieron en un incendio de 1765. Cfr. Centeno Carnero, 1996: 81.

${ }^{16}$ El 2 de mayo de 1589 otorgó un poder a Pedro de Yrala, vecino de Vera Cruz, y a Fernán López de Castro y Juan López Morilla, estos últimos vecinos de la ciudad de México, quienes debían cobrar en su nombre, de los herederos y albaceas testamentarios de Diego Merino Ortiz, fallecido en la ciudad de Vera Cruz, quinientos reales. Diego Merino le adeudaba dicha cantidad por un "brinco" de oro y ámbar que el pintor le había entregado para que su venta. AHPSe. SPNSe.: Legajo 14362, oficio 21. Libro 5. 1589 , fols. 326 rto-327 rto. El 25 de junio de 1590 demandó la cuantía económica (cincuenta ducados) resultante de la venta de una prenda de oro y nácar que envió a México, apoderando para ello al veedor de flotas para la Nueva España don Martín Romero. AHPSe. SPNSe.: Legajo 1603, oficio 3. Libro 3. ${ }^{\circ}$ de 1590 ., fols. 308 rto-309 rto.

17 El 24 de enero de 1590 apoderó al madrileño Juan García de Losada, para que demandara al italiano Juan Andrea Vaiani, estante en Madrid, quinientos reales por una deuda que el pintor le pagó en su nombre al sevillano Francisco García. AHPSe. SPNSe.: Legajo 14368, oficio 21. Libro 1. ${ }^{\circ}$ 1590, fols. 1088 rto-1089 rto. El 6 de julio de 1590 recibía de Baltasar del Alcázar, administrador de los bienes y rentas de la señora doña Bernardina Vicentelo, condesa de Gelves, mil reales de plata. AHPSe. SPNSe.: Legajo 14373, oficio 21. Libro 6. ${ }^{\circ}$ 1590, fols. 586 rto. Quizá relacionada con su quehacer artístico podría estar la gestión realizada el 12 de julio de dicho año para cobrar unos dineros que le adeudaba la fábrica parroquial de San Miguel de Jerez de la Frontera. No obstante, no se alude a ninguna obra. Cfr. Muro Orejón, 1935: 62.

18 Aquí ya es vecino de la Magdalena, collación con una colonia importante de pintores. LóPEZ MARTíNEZ, 1928a: 108-110. Palomero PÁramo, 1983: 387-388.

19 Palomero PÁramo, 1983: 438-439.

Arch. esp. arte, LXXXVII, 345, ENERO-MARZO 2014, 15-28 ISSN: 0004-0428, eISSN: 1988-8511, doi: 10.3989/aearte.2014.02 
niaría, de haberse realizado, el inicio de la sustitución de las tablas por los lienzos en los retablos sevillanos ${ }^{20}$. A nuestro entender, las precisiones incluidas en el contrato sobre cómo debían montarse los lienzos, su calidad y el hecho de que Jerónimo se responsabilizara de ello, se justificarían por sus amplios conocimientos en el uso de la tela en los retablos, novedoso soporte entonces en los conjuntos sevillanos ${ }^{21}$.

También en 1591 se fecha una nueva petición del pintor para la cobranza de dineros que le adeudaban en las Indias ${ }^{22}$. Y es en este año, el 20 de noviembre, cuando una enfermedad le llevará a redactar su testamento ${ }^{23}$. Reconociéndose vecino de la collación de la Magdalena, solicitó ser enterrado en este templo. Aparte de las tradicionales peticiones de misas y rezos por su alma, encontramos asentadas cuestiones de índole económica, relacionadas con adeudos. Su esposa, doña Antonia de Liaño, aparece como la destinataria de la mayor parte de sus mandas testamentarias. Sin embargo, y atendiendo a que no tenía hijos, Jerónimo declaraba como legítima heredera universal de todos sus bienes a su madre, Catalina Rodríguez ${ }^{24}$. Como era costumbre, en un acto de caridad, ordenaba que el esclavo que tenía a su servicio quedara libre una vez que falleciera su mujer. Finalmente, nombraba por sus albaceas testamentarios a su esposa y al fraile trinitario Baltasar Díaz de Alcocer ${ }^{25}$.

Posiblemnente el estado de salud del pintor no revistiera especial gravedad, pues unos meses más tarde lo encontramos actuando como fiador en el concierto firmado en febrero de 1592 por Juan de Oviedo el Mozo para el retablo mayor de la parroquia de Consolación de Cazalla de la Sierra $^{26}$. Sin embargo, es probable que en la primavera de 1592 su salud empeorara y que, por ello, decidiera redactar un codicilo complementario a su testamento. Escriturado el 22 de mayo, en él quedan perfectamente consignadas, entre otras, cuestiones relativas a su trabajo, deudas y hacienda, en un deseo de evitar a su esposa problemas ante la inminente llegada de su muerte ${ }^{27}$. Éste es, sin duda, el documento más interesante que presentamos, pues pone de relieve la dimensión artística de Jerónimo Sánchez Coello. Gracias al mismo, podemos conocer aspectos como su dedicación a diferentes géneros pictóricos; su trabajo al servicio de una selecta clientela local, que pensamos le consideró por ser conocedor y fiel seguidor de Tiziano; su exportación de pinturas a América; y, finalmente, las obras que poseyó el artista, entre las que, según él mismo declara, figuraban lienzos del maestro veneciano.

La primera de las anotaciones del codicilo refiere su participación en un retablo que había sido encargado por don Alonso de Salinas, contador mayor del VII Duque de Medina Sidonia. No se alude a la ubicación del mismo, pero debió destinarse a alguna iglesia de la capital del ducado, Sanlúcar de Barrameda, la cual bajo el patrocinio de los VII duques, don Alonso Pérez de Guzmán y doña Ana de Silva y Mendoza, se encontraba en plena renovación de sus templos y ajuares. No sería extraño que el promotor de la obra hubiera sido realmente el propio Duque, quien figuró detrás de muchos de los encargos artísticos de sus fundaciones. Desafortunadamen-

20 Palomero PÁramo, 1983: 387.

21 Sobre el protagonismo ejercido por otro pintor también formado en Venecia, El Greco, en la introducción del lienzo en los retablos toledanos, cfr. BRUQUetAs GALÁn, 2002: 275-276. Sobre el caso sevillano, cfr. MALO LARA, 2006.

22 El 24 de julio apoderó a don Pedro de Mendoza para que demandara a los herederos de Diego Merino Ortiz quinientos treinta y un reales y dos maravedíes de principal con mil doscientos cuatro maravedíes de costas que se le adeudaban. AHPSe. SPNSe.: Legajo 12537, oficio 19, libro 4. ${ }^{\circ} 1591$, fols. 449 rto-vto.

23 AHPSe. SPNSe.: Legajo 1605, oficio 3, Libro 2. ${ }^{\circ} 1591$, fols. 1389 vto-1391 rto.

24 Estos bienes estaban valorados en los doscientos ducados que él aportó al matrimonio. El resto quedaría en manos de su mujer, a quien entregaba el tercio y remanente del quinto de todos sus bienes y derechos. Estipuló que se le devolviesen los setecientos ducados que ella le entregó en dote.

25 Con este religioso hubo de mantener una estrecha amistad, relacionada con el encargo recibido meses atrás del monasterio sevillano de las Santas Justa y Rufina, pues actuó como otorgante del contrato de su retablo mayor.

26 López Martínez, 1928b: 162-164. Palomero PÁramo, Ob. cit.: 354-358.

27 AHPSe. SPNSe.: Legajo 8441, oficio 14, libro 2. ${ }^{\circ}$ de 1592, ff. 311 rto-315 rto.

Arch. esp. arte, LXXXVII, 345, ENERO-MARZO 2014, 15-28

ISSN: 0004-0428, eISSN: 1988-8511, doi: 10.3989/aearte.2014.02 
te, el documento refiere básicamente cuestiones monetarias del retablo, que consta estaba concluido $^{28}$. No obstante, nos permite conocer a los artistas que colaboraron con él: los escultores Miguel Adán y Diego del Campo, y el pintor Juan de Saucedo. Aunque no logramos identificar este conjunto ${ }^{29}$, es interesante saber que nuestro pintor, un artista vinculado a la Corte de Felipe II, participó en una obra patrocinada en el círculo del VII Duque de Medina Sidonia, quien es sabido admiró y emuló empresas artísticas del monarca ${ }^{30}$. Además, más adelante comentaremos otro posible vínculo entre el Duque y Jerónimo.

Otra serie de pinturas que recoge el codicilo es un lote de obras suyas que había enviado a las Indias con el comerciante Pedro Aguilar de la Sal ${ }^{31}$. Quizás entre las mercancías remitidas por éste a Nueva España en 1590 se encontrasen las pinturas referidas por Jerónimo: seis representaciones de Cristo Crucificado, seis "varoniles de Cristos Rostros" - probablemente, retratos de la Santa Faz de Cristo-, dos figuras del Salvador glorioso, otras dos de San Francisco, un San Jerónimo, un Cristo con la cruz a cuestas, una imagen de Nuestra Señora y "una patria", posible alusión a un paisaje o cartografía. Como podemos comprobar, se trata, casi en su totalidad, de pinturas devocionales, algunas de ellas en serie, destinadas a un mercado americano, en líneas generales, menos exigente -y menos controlado por el gremio- que el local. Este mercadeo de su obra con América no fue una excepción, ya que consta que envió otros lienzos suyos para su venta en Nueva España ${ }^{32}$. Además de las pinturas entregadas a Aguilar de la Sal, también doró y estofó una cama para este rico comerciante y realizó para su casa sevillana un San Francisco y un retrato "de la esposa del señor Jerónimo de Jáuregui", que no era sino una hermana del mercader, llamada Isabel Martínez ${ }^{33}$. Aparece ya aquí un género, el del retrato, que veremos hubo de constituir una de sus grandes facetas creativas.

Otro personaje de cierta relevancia que aparece como su cliente es don Pedro García de Neira, natural de Medina de Rioseco y avecindado en Sevilla, dedicado al comercio de libros con América ${ }^{34}$. Para él Jerónimo realizó una serie de pinturas, entre ellas, un "Ecce Homo copiado del Tiziano". Hallamos aquí una clara evidencia del aprecio que hubo de despertar, entre la clientela, su condición de conocedor de primera mano de la obra del veneciano. También, una muestra más del éxito de esta iconografía devocional tanta veces copiada de Tiziano, uno de cuyos mejores originales se encuentra en el Museo del Prado, procedente de la colección de Carlos V (fig. 3). Además de esta obra, pintó para el comerciante vallisoletano una Sagrada Familia con san Juanito, una Santa Catalina, un San Jerónimo, un San Francisco de Paula, una María Magdalena y un San Francisco de Asís, devociones todas ellas populares en la época. Además, hizo para él un "retrato del príncipe Felipe", futuro Felipe III, que pudo

${ }^{28}$ Declaró que su labor había sido tasada en doscientos noventa y cinco ducados, de los que debía percibir aún mil seiscientos treinta y cinco reales.

29 Se sabe que Miguel Adán realizó, entre 1592 y 1594, el destruido retablo mayor del monasterio de Santo Domingo de Sanlúcar de Barrameda, en colaboración con otros maestros. Cfr. Palomero PÁramo, Ob. cit.: 214-216. El conjunto en el que intervino con Jerónimo hubo de ser contratado con anterioridad a éste.

30 Serrera Contreras, 1998: 167-183. Cruz Isidoro, 2011: 97.

31 Fue un destacado exportador. En 1590 sus embarques en la flota de Nueva España fueron calculados en torno a veinte mil pesos. Cfr. GARCíA FuENTES, 1997: 254.

32 Se trata de otro envío que hizo mediante Martín Romero, a través de los corredores Jerónimo Rueda y Rodrigo Montero, agentes comerciales de Nicolás Nambeatengo, debiendo percibir el dinero generado por dicha venta. No se especifica en este caso ni el número ni la temática de las obras remitidas.

33 Su nombre lo hemos extraído de Jordán De UrRiés y AZARA, 1899: 9 y 20. Por todas estas obras tenía recibidas varias partidas de especies: diversos tejidos, una caja de doce libras de carmín de Indias, dos fanegas de trigo, dos barriles de aceitunas de Valladolid, y una arroba de velas de Granada. Solicitó el pintor que se debían ajustar las cuentas para quedar en paz con Pedro Aguilar de la Sal.

34 Torre Revello, 1962: 13. Álvarez Márquez, 2007: 333.

Arch. esp. arte, LXXXVII, 345, ENERO-MARZO 2014, 15-28 ISSN: 0004-0428, eISSN: 1988-8511, doi: 10.3989/aearte.2014.02 


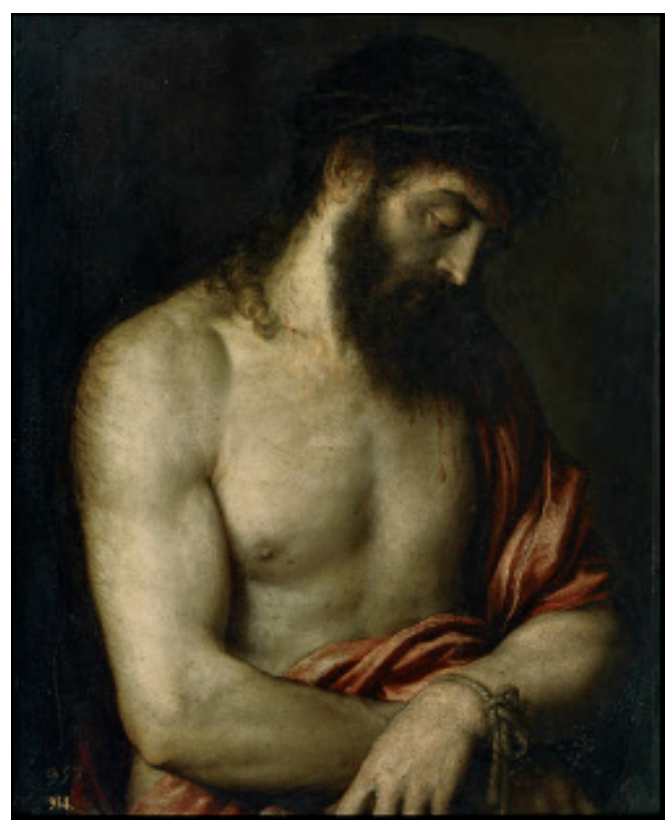

Fig. 3. Tiziano. Ecce Homo. 1547. Museo Nacional del Prado, Madrid.

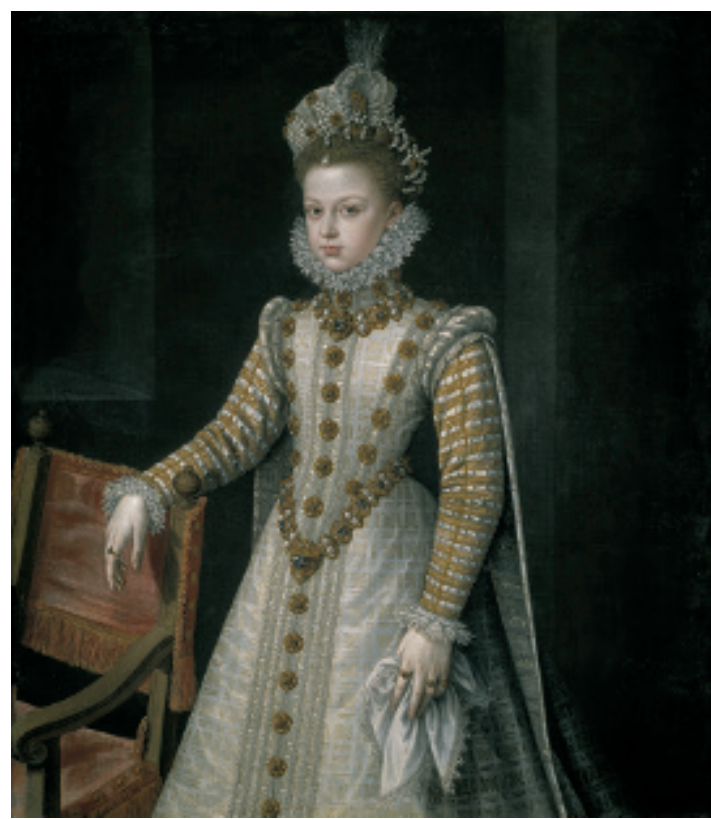

Fig. 4. Alonso Sánchez Coello. Isabel Clara Eugenia. 1579. Museo Nacional del Prado, Madrid.

seguir el ejemplo de los retratos que tuvo ocasión de contemplar en el taller cortesano de su hermano ${ }^{35}$.

Sigue el más importante de los encargos privados recibidos por Jerónimo en sus años sevillanos, al menos del que tengamos constancia documental. Éste fue promovido por el Canónigo magistral de la Catedral hispalense don Alonso Coloma de Saa (c.1556-1606). Graduado en Teología y autor de composiciones poéticas, desarrolló una ascendente carrera eclesiástica, en la que se relacionó con la Corte y, directamente, con el rey Felipe II. Canónigo de la Catedral de Sevilla desde 1588, residió en la capital andaluza hasta $1596^{36}$. Durante su estancia sevillana, Coloma demandó a Jerónimo una extensa galería de retratos de hombres y mujeres ilustres, que acaso formó parte de un gabinete o studiolo, propio de la mentalidad humanista, junto a la rica biblioteca que poseyó el canónigo; no sabemos si, quizás, incluyendo las rarezas y curiosidades habituales en estas colecciones. Ejemplos similares se dieron en Sevilla, destacando el muy co-

35 Este encargo fue valorado en ochocientos setenta reales, a los que se sumarían un cofre y un arca de madera. Jerónimo declaró haber entregado a la fecha el Ecce Homo, la Sagrada Familia, el San Francisco de Asís y el San Francisco de Paula; por ellos había percibido los citados muebles y doscientos cuarenta y ocho reales, debiéndosele aún los seiscientos veintidós reales restantes. Ordenó que los demás lienzos, que tenía concluidos en su taller, fueran entregados cuando se completase el pago. De dicha cuenta debían excluir el retrato del Príncipe, también terminado y que había sido resultado de otro encargo. Tras esta anotación, recoge el documento otras reclamaciones de Jerónimo a los comerciantes Francisco de Angena, Juan Manfredi y Francisco Ximeno, aunque sin aclarar, en estos casos, la naturaleza de los adeudos.

36 Perteneciente a una familia noble del Levante hispano, fue hijo de don Juan Coloma, I conde de Elda. Participó en la regulación de los estudios universitarios en Valencia, para lo cual fue nombrado por Felipe II visitador de su Universidad en 1597. Ocupó dos sedes episcopales importantes, la de Barcelona en 1599 y la de Murcia-Cartagena en 1603. En Murcia residiría hasta su muerte. Cfr. Segui Cantos, 1992: 325-346. Fernández Luzón, 2005: 99. Guill ORTEGA, 2010: 35-47.

Arch. esp. arte, LXXXVII, 345, ENERO-MARZO 2014, 15-28

ISSN: 0004-0428, eISSN: 1988-8511, doi: 10.3989/aearte.2014.02 
nocido de don Gonzalo Argote de Molina, caballero veinticuatro que encargó en 1571 al hermano de nuestro protagonista, Alonso Sánchez Coello, una galería de ilustres personajes para su casa sevillana, proyección de la que poseyó Felipe II en el Pardo, en la que participó también Alonso. Se sabe que Jerónimo estuvo al tanto de este encargo sevillano de su hermano, pues actuó como intermediario en gestiones generadas por el mismo ${ }^{37}$. Años más tarde, sería él quien realizara una galería similar para Coloma, religioso vinculado a la Corte que bien pudo tener conocimiento de las series de retratos citadas.

Tras este tipo de encargos es sabido que existe una clara intencionalidad, una evidente admiración e identificación de las ideas del propio promotor con los representados, como si de una proyección ideológica se tratase ${ }^{38}$. En la galería de retratos de Coloma se reflejaba una firme admiración por la monarquía española y un claro compromiso con la Iglesia Católica. Aunque en el plano religioso resulte llamativa la aparición de personajes vinculados al protestantismo o la religión musulmana, su presencia pudo deberse a un afán por mostrar el camino erróneo y herético, personificado en figuras que se contrapondrían a destacados defensores del catolicismo. En cualquier caso, sería un palpable reflejo de los conflictos religiosos que dividían entonces a Europa.

La galería se componía de treinta y ocho retratos ${ }^{39}$. Aunque no se refieren sus medidas, debieron ser de formato pequeño, habida cuenta su elevado número y el precio en el que fueron tasados, sólo cien ducados ${ }^{40}$. Probablemente la mayoría de ellos fueron captados de busto o de medio cuerpo, pues sólo en dos ocasiones indica el pintor representaciones de cuerpo completo. Es el caso de los dos retratos con los que Jerónimo inicia la relación, quizás los más destacados: uno del rey Felipe II y otro del propio canónigo. Coloma encargó al pintor, además, otro retrato "pequeño" de su monarca. Dada la nómina que sigue, comprobamos que Coloma quiso exaltar la monarquía española, pasada y presente, ensalzando a sus miembros más ilustres. A Felipe II se unían los Reyes Católicos, el emperador Maximiliano de Austria (en el documento aparece como "el conde de Flandes", que fue la parte heredada por la casa española), la reina Juana la Loca, su hijo el Emperador Carlos V y la esposa de éste, doña Isabel de Portugal. También figuraba el retrato de doña María Tudor, Reina de Inglaterra y mujer de Felipe II. Igualmente, las imágenes de los hijos del monarca: los príncipes don Diego, don Felipe (futuro Felipe III) y la infanta doña Isabel Clara Eugenia, su primogénita y candidata española a ocupar el trono de Francia. También se incluyen otros monarcas de la casa reinante: el rey don Sebastián y su madre, la castellana doña Juana de Austria, hermana de Felipe II. Con su presencia se reforzaba, sin duda, la idea de los derechos dinásticos del monarca español sobre Portugal y, con la descripción de su árbol genealógico, también sobre el resto de territorios europeos gobernados por él.

Es posible que Jerónimo se inspirara para estos retratos en modelos que formaban parte de la colección real, y que bien pudo conocer en su etapa madrileña, siguiendo la estela del retrato cortesano codificado por Alonso Sánchez Coello (fig. 4); una tipología que sería admirada y solicitada por la clientela sevillana, como se deduce de este sustancioso encargo a Jerónimo y de colecciones como la antes citada de Argote de Molina.

37 Kusche, Ob. cit.: 366-372.

38 Serrera Contreras, 1990: 37-44. Kusche, 1992: 1-37. Falomir Faus, 1999: 125-140.

39 Hemos logrado identificar treinta y siete, pues el nombre de uno de ellos es completamente ilegible.

40 Resultan casi veintinueve reales por retrato. Esta cifra es baja si la comparamos con el precio que alcanzaron retratos pequeños que Jerónimo hizo en Sevilla. Por ejemplo, varios de ellos fueron estimados en seis ducados, es decir, sesenta y seis reales. A estos cien ducados habría que sumarle, según recoge el documento, dos cahices de trigo, que no aumentarían mucho el precio medio por obra. Aunque no es del todo comparable, su hermano Alonso cobraba por retratos similares una cantidad que oscilaba entre diez y quince ducados. Cfr. Kusche, 2003: 368, 380. Quizá Jerónimo aceptara este trabajo a bajo precio para congraciarse con un comitente bien posicionado socialmente, que podría reportarle nuevos encargos.

Arch. esp. arte, LXXXVII, 345, ENERO-MARZO 2014, 15-28 ISSN: 0004-0428, eISSN: 1988-8511, doi: 10.3989/aearte.2014.02 
En la galería de Coloma tampoco faltaban glorias del pasado histórico o mítico de los reinos hispánicos en el Medievo, como Bernardo del Carpio, el Conde de Castilla Fernán González, el Cid Campeador o el rey Alfonso X el Sabio. Tampoco se olvidan a héroes de las guerras del Imperio, pues aparecen los retratos del Gran Capitán y de don Juan de Austria. Todas estas figuras fueron habituales en las galerías de la época ${ }^{41}$. Menos frecuentes, pero presentes en la colección de Coloma, son los retratos del conde de Oliveto (don Pedro Navarro, célebre por su actuación en las Guerras de Italia y del Norte de África) y el del Alcalde de la Casa y Corte don Rodrigo Ronquillo, destacado miembro del bando realista durante las Guerras Comuneras en Castilla.

La colección del Canónigo también dio cabida a destacadas figuras del ámbito internacional. Así, figuran personalidades vinculadas a la herejía protestante, como monarcas protagonistas del conflicto religioso vivido en Inglaterra: las reinas Ana Bolena e Isabel I, quien mandó decapitar en 1587 a su prima, la católica reina de Escocia María Estuardo, también retratada aquí ${ }^{42}$. Relacionada igualmente con las corrientes protestantes en Italia, y presente en esta galería, la efigie de Julia Gonzaga. También se aludía en la colección al conflicto religioso vivido en Francia entre católicos y hugonotes, mediante la figura del monje dominico Jacques Clément (15671589), partidario del bando católico y asesino del rey francés Enrique III ${ }^{43}$. Tampoco faltaron figuras alusivas a la religión y al poder musulmán, pues Coloma poseyó un retrato "del gran Tamerlán", conquistador timúrida del siglo XIV, además de la efigie de "una turca", posible alegoría del infiel musulmán y del imperio que amenazaba la paz católica desde Oriente ${ }^{44}$. En oposición a estos retratos, figuraría a ojos de Coloma la efigie de Jorge Castrioto, más conocido como Escanderbey, el épico capitán y rey de Albania que mantuvo a raya al Turco durante la primera mitad del siglo $\mathrm{XV}^{45}$, igual que lo habían logrado el Emperador Carlos $\mathrm{V}$ y su hijo. Volviendo al ámbito español, encontramos dos retratos de figuras que, probablemente, fueron admiradas por Coloma desde el punto de vista religioso, como son doña Teresa Enríquez ${ }^{46}$, duquesa de Maqueda, conocida como "la Loca del Sacramento", y el enérgico predicador San Vicente Ferrer, paisano del eclesiástico.

En otro orden, figuraban hombres de ciencias y de letras: las efigies de Ptolomeo, Cicerón y Dante Alighieri. Se trata de un repertorio un tanto reducido, que puede sorprender dada su condición de hombre instruido y poeta, y también en comparación con otras galerías de la época. En cualquier caso, demuestra su afinidad al espíritu humanista de su tiempo.

De esta extensísima nómina de retratos faltaban por entregar al Canónigo, en el momento de la redacción del codicilo, doce ${ }^{47}$, debido a que aún no se le había satisfecho al pintor el total del

41 Como en la colección de Alvia, Secretario del Consejo de Guerra. Cfr. CHECA Y MoRÁN, 1985: 162. Presentes muchas de estas figuras también en la colección de Argote de Molina, no incluye sin embargo la de Coloma ninguna de las personalidades de la intelectualidad sevillana contemporánea que abundan en la de Argote.

42 También cita el documento un retrato de "Enrique setimo rey de Escocia". Creemos que debe tratarse de un error, ya que no existe un monarca escocés con dicho nombre. Debe tratarse de Enrique VII de Inglaterra.

43 En el documento se le menciona como "el frayle que mato al rey de Francia".

${ }^{44}$ Nombres del imperio turco también figuraron, por ejemplo, en la galería de Argote de Molina, con los retratos de Solimán el Magnífico y de su hijo Selim.

45 Su figura fue muy popular en la época gracias a La crónica del esforzado príncipe y capitán Jorge Castrioto, rey de Epiro o de Albania (Madrid, 1597), que fue recogida en un romance de Góngora de 1586, así como gracias a otras obras que relataron sus hazañas. Cfr. CASADO SANTOS, 2002: 485-495.

${ }^{46}$ Entendemos que existe un error en el documento a la hora de mencionar a la duquesa de Maqueda, que es nombrada como "Antonia", nombre que no ostentará ninguna mujer de esta casa hasta bien entrada la siguiente centuria.

47 Éstos eran los de los emperadores Carlos e Isabel, las reinas Ana, Juana y María Estuardo, y el rey Enrique VII, además de los de Teresa Enríquez, el Alcalde Ronquillo, Jorge Castrioto, San Vicente Ferrer, el Conde Fernán González y Cicerón.

Arch. esp. arte, LXXXVII, 345, ENERO-MARZO 2014, 15-28

ISSN: 0004-0428, eISSN: 1988-8511, doi: 10.3989/aearte.2014.02 
dinero acordado ${ }^{48}$. La colección de Coloma, que le acompañaría tras abandonar Sevilla, hubo de dispersarse después de la almoneda de sus obras de arte realizada en Murcia por su fallecimiento en $1606^{49}$.

Realizó Jerónimo en Sevilla otros encargos para nobles y religiosos, principalmente retratos, género en el que hubo de ser considerado un auténtico especialista. Así, para el caballero de la orden de Santiago Juan de Saavedra, apodado "el Turquillo", pintó tres retratos grandes, uno de su persona, otro de su hijo don Bernardo de Saavedra y el último de su esposa, doña Francisca Enríquez de Sandoval y Rojas ${ }^{50}$. Para don Diego de Melo realizó un retrato "chico" valorado en seis ducados, otro de pequeño formato de la Marquesa de Tarifa, doña Ana Téllez-Girón, estimado también en seis ducados, y uno de cuerpo entero del alcalde Juan Gutiérrez de Solórzano, tasado en quinientos reales ${ }^{51}$.

También hizo varias pinturas para don Álvaro de Losada Quiroga, Canónigo y Tesorero de la Catedral de Sevilla y Camarero del Cardenal don Rodrigo de Castro ${ }^{52}$. Nos llama la atención cómo, en esta ocasión, describe el asunto de uno de estos lienzos, que representaba "una imagen de Nuestra Señora con un Niño descansando y San Juan y Santa Ana y San José del natural y tienen un gato y un perro y los niños tienen unas cerezas en las manos". A nuestro entender, esta obra pudo ser un trasunto, con ligeras variantes, del conocido lienzo de Tiziano La Madonna de las cerezas, propiedad del Kunsthistorisches Museum de Viena (fig. 5), siendo, así, una muestra más de su reputación como copista de obras del veneciano. Nos resulta sugerente advertir el hecho de que este religioso íntimamente ligado al Cardenal don Rodrigo de Castro se interesara por poseer una obra de un artista de formación italiana como Jerónimo; más cuando justamente se ha señalado a Castro como una figura que pudo ser relevante en el coleccionismo y la difusión del arte italiano en la Sevilla del momento ${ }^{53}$. Curiosa es la mención expresa sobre las figuras anecdóticas del perro y el gato, aspectos estos que, como es sabido, solían ser rechazados entonces en aras del decoro. Además de este lienzo, realizó para don Álvaro de Losada los retratos de busto de doña Blanca Enríquez y doña Antonia Enríquez, posiblemente familiares del mismo ${ }^{54}$.

De esta pródiga relación de obras realizadas por Jerónimo podemos extraer una serie de conclusiones sobre su labor como pintor, en parte ya expresadas. Además de su participación en la pintura y policromía de retablos, que acaparaban entonces buena parte del trabajo de los artistas que laboraban en Sevilla, es más que notoria su especialización como autor de retratos, siguiendo la estela de su hermano Alonso. También resulta clara su dedicación a la pintura religiosa destinada a la devoción privada, en ocasiones, como copista de Tiziano, y otras veces realizando obras devocionales en serie para su exportación al mercado americano.

48 Declaró haber recibido cien reales y seis fanegas de trigo, por lo que se le debía cahiz y medio de trigo más mil reales. También se le debía otro retrato que Coloma le había encargado después, y que era una miniatura de una tal doña Luisa de Castro, pintada en un naipe y valorada en cien reales.

49 Se sabe que los pintores Jerónimo de Espinosa y Juan de Alvarado adquirieron en almoneda pública obras de la colección de Coloma. Cfr. LóPEZ JiMÉNEZ, 1966: 6; 1974: 30; AgÜERA Ros, 1994: 84.

${ }^{50}$ Por estos retratos había recibido trescientos reales, cuando el valor de cada uno rondaba los veinte ducados; por ello, pedía a sus albaceas que cobrasen el resto que se le adeudaba. Se menciona a Juan de Saavedra en DE MAYORALGO Y LODO, 1996-1997: 19.

${ }^{51}$ De este encargo había recibido cuatro fanegas de trigo a veinte reales la fanega, por lo que el resto debía ser abonado a sus herederos. También añade Jerónimo otra deuda de quinientos reales contraída con él por Juan Andrea Barán por otra pintura que en, este caso, no especifica.

52 Yace enterrado en la capilla de la Virgen de la Antigua de la Catedral. Cfr. ANTEQuera Luengo: 77.

53 SALORT PONS, 2005: 62-63.

${ }^{54}$ El primer lienzo comentado estuvo valorado en cincuenta ducados, una suma nada despreciable. Los retratos, en cien reales. De todo ello sólo había recibido Jerónimo seis fanegas de trigo, por lo que mandaba a sus albaceas cobrar el resto.

Arch. esp. arte, LXXXVII, 345, ENERO-MARZO 2014, 15-28 ISSN: 0004-0428, eISSN: 1988-8511, doi: 10.3989/aearte.2014.02 


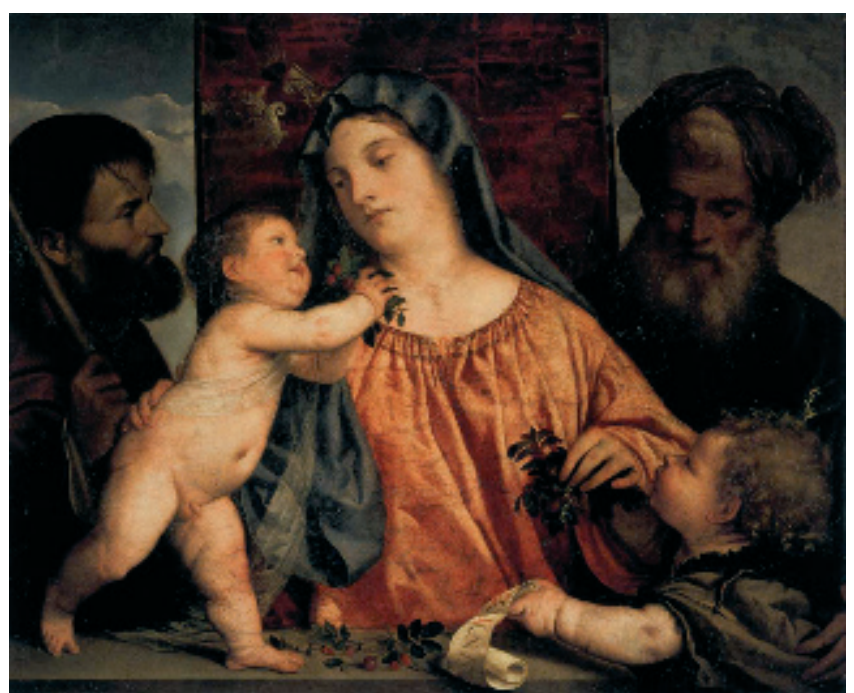

Fig. 5. Tiziano. La Madonna de la cerezas. H. 1516-1518. Kunsthistorisches Museum, Viena.

Además de las sustanciosas noticias sobre la obra de nuestro artista, el documento recoge, finalmente, una serie de interesantes referencias sobre pinturas que poseyó; si bien el codicilo no relaciona la colección pictórica que Jerónimo pudo tener. La información que poseemos la debemos al hecho de que el pintor reclamase el pago por seis obras que le pertenecían y que no tenía en su poder, debido a que las había prestado tiempo atrás. Por lo que se deduce, querría cobrar una especia de "renta" generada por haberlas cedido en préstamo. No expresó Jerónimo que vendiera definitivamente estas obras a sus poseedores temporales, pero tampoco que tuvieran que ser devueltas. Lo que parece seguro es que se trataba de las mejores pinturas que tuvo, pues entre ellas, según declara, se encontraban originales de Tiziano.

En primer lugar, menciona cuatro cuadros que tenía en casa del antes citado comerciante Pedro Aguilar de la Sal; concretamente, dos lienzos grandes que representaban a Santa María Magdalena y a San Jerónimo, sin citar su autor, así como una pintura de un "Cristo que toma la ropa con dos sayones arrimados a la columna" y un "Ecce Homo", ambas obras de mano de Tiziano. No son éstos los únicos originales del veneciano que refiere, pues a continuación indica otros dos lienzos del mismo: un "Sepulcro de Tiziano que no está acabado" -se trataría de una representación del Entierro de Cristo-y un "Ecce Homo también de Tiziano". Estas dos pinturas las había dado en préstamo al tesorero Juan de Mesa, "que vive en las casas del Duque de Me-

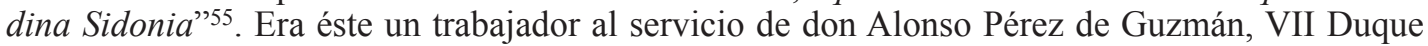
de Medina Sidonia, a quien ya mencionamos antes como posible comitente de un retablo en el que intervino Jerónimo en Sanlúcar de Barrameda. No habría sido extraño, por tanto, que el dueño temporal de estas obras de Tiziano hubiera sido realmente el propio Duque, de quien ya recordamos su admiración por el arte patrocinado en la Corte de Felipe II.

En cuanto al hecho de que Jerónimo poseyera originales de Tiziano, es algo difícil dado el alto precio de sus obras y la gran demanda existente. Podría pensarse que estas obras fuesen realmente copias realizadas por él y que intentara hacerlas pasar por originales del veneciano para que, de este modo, alcanzasen una mayor valoración. No obstante, no sería tampoco extraño que hubiera adquirido en Venecia pinturas de la última etapa del maestro, cuando tenía el favor real

55 Encontramos una noticia de la vinculación del tesorero Juan de Mesa con el Duque en SAlas Almela, 2008 : 266 , nota 160 .

Arch. esp. arte, LXXXVII, 345, ENERO-MARZO 2014, 15-28

ISSN: 0004-0428, eISSN: 1988-8511, doi: 10.3989/aearte.2014.02 


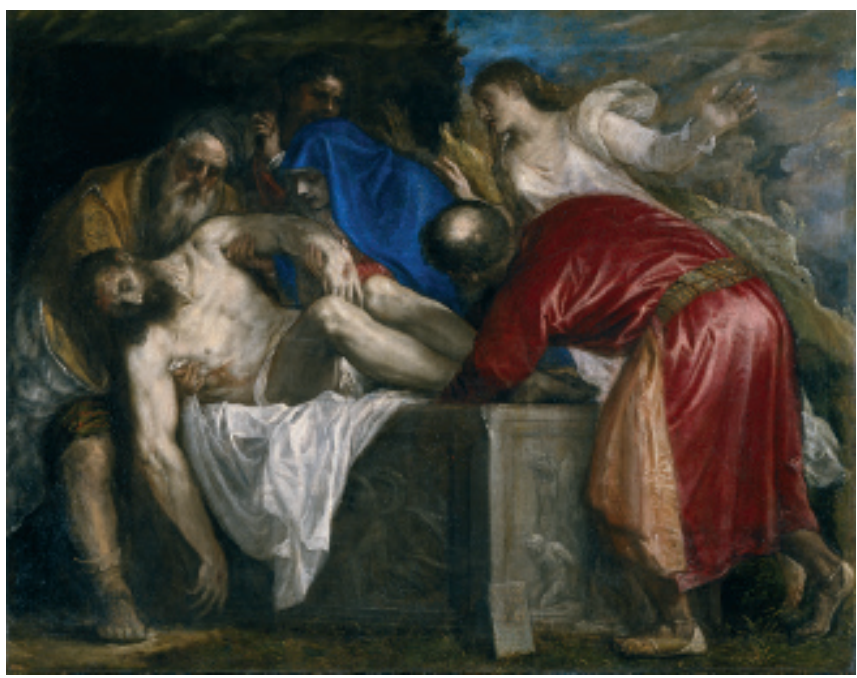

Fig. 6. Tiziano

El entierro de Cristo. 1559. Museo

Nacional del Prado, Madrid.

y el posible apoyo económico de su hermano Alonso. En tal caso, estas pinturas debieron ser secundarias y de pequeño formato, estando incluso alguna de ellas inacabada, como él mismo indicó. De ser cierto, permitiría establecer la presencia de obras de Tiziano en la capital andaluza en fecha temprana. Serían todas ellas representaciones devocionales de la Pasión de Cristo que, como es sabido, fueron especialmente cultivadas por Tiziano, queridas y demandadas por sus clientes -recuérdense obras como el Ecce Homo o el Entierro de Cristo (fig. 6) pertenecientes al Museo del Prado-, y muy copiadas por sus seguidores, como vimos que hizo el propio Jerónimo.

No sabemos si estas obras llegaron a estar un tiempo en el taller sevillano del artista, donde podrían haber sido un reclamo importante para clientes y también para pintores y posibles aprendices; o, por el contrario, permanecieron siempre en ámbitos privados. En cualquier caso, queda patente que el interés por la obra de Tiziano se había asentado, de la mano de nuestro protagonista, en la clientela de la capital andaluza. Una clientela que solicitaba copias de sus obras y el préstamo de unos cuadros que, aunque quizás secundarios y menores, mostrarían un arte muy distinto del dominante en la Sevilla de la época.

Pensar que la factura deshecha del anciano Tiziano pudo dejar huella en la técnica pictórica de Jerónimo es algo que no podrá saberse hasta que no aparezcan obras de su mano. Si tuviéramos en cuenta el conocido testimonio de Pacheco sobre los "borrones" que Jerónimo declaró haber visto hacer a Tiziano sobre obras más acabadas ${ }^{56}$, podría aventurarse que el aprendiz pudo no ser partidario de este modo de pintar. De ser así, quizá en ello influyera su formación primera junto a su hermano Alonso, quien hubo de transmitirle su técnica depurada de herencia flamenca $^{57}$. Independientemente del influjo técnico del veneciano en la pintura de Jerónimo -y, por extensión, en la sevillana, que no se constata si no puntualmente y en fechas más tardías ${ }^{58}$, en

56 "Siendo muy viejo (como refería un hermano de Alonso Sánchez, valiente retratador de Filipo II, que estuvo en su casa) daba borrones sobre cosas excelentes, con lástima de los que las miraban”. Cfr. PACHECO, 1649, Ed. 2001: 417.

57 Respecto al limitado influjo de Tiziano sobre Alonso Sánchez Coello ya se pronunció Pérez SÁnCHEZ, 1976: 147-148.

58 Entre los pintores que muestran primero en Sevilla la asimilación técnica de la pintura veneciana, se encuentra Juan de Roelas, quien muestra un venecianismo más vinculado a la obra de Tintoretto que a la de Tiziano. Cfr. PÉREZ SÁNCHEZ: 1976: 153-154. VALDIVIESO GONZÁLEZ, 1978; 1986; 2003; 2008.

Arch. esp. arte, LXXXVII, 345, ENERO-MARZO 2014, 15-28 ISSN: 0004-0428, eISSN: 1988-8511, doi: 10.3989/aearte.2014.02 
obras de Tiziano como las que pudo traer a la capital andaluza y, de un modo más frecuente en los grabados de su obra, los artistas encontraron "el esquema compositivo, la solución iconográfica propuesta por el pintor veneciano que se demostró evidentemente válida por mucho tiempo para la piedad española" 59 .

Jerónimo Sánchez Coello firmó el codicilo de su testamento el 22 de mayo de 1592 (fig. $7)^{60}$. Después de esta fecha, no hallamos rastro de él hasta que el 9 de julio del mismo año, en un poder general otorgado por su mujer, doña Antonia de Liaño se declara viuda ${ }^{61}$. Por lo tanto, el óbito del pintor debió acaecer poco des-

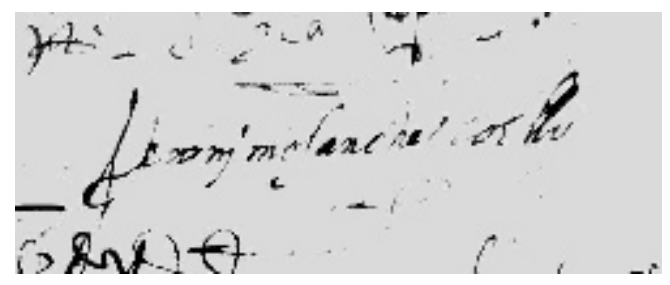
pués de redactar sus últimas voluntades.

Intentar identificar alguna de las numerosas obras que ahora sabemos realizó en Sevilla escapa a los límites de este estudio. Es ésta una tarea que se presenta, por lo demás, muy complicada hasta que no se encuentren obras firmadas por el pintor.

\section{BIBLIOGRAFÍA}

Agüera Ros, José Carlos, Pintura y sociedad en el siglo XVII. Murcia, un centro del barroco español, Murcia, 1994.

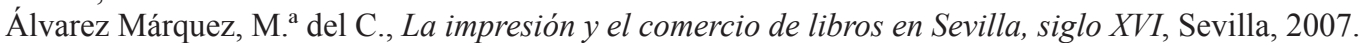

Antequera Luengo, Juan J., Memorias sepulcrales de la Catedral de Sevilla. Los manuscritos de Loaysa y de González de León, Facediciones.

Bruquetas Galán, Rocío, Técnicas y materiales de la pintura española en los Siglos de Oro, Madrid, 2002.

Casado Santos, M. ${ }^{a}$ José, "La versión jocosa de la historia de Jorge Castrioto: Escanderbey, comedia burlesca de Felipe López", en Memoria de la palabra, Actas del VI Congreso de la Asociación Internacional Siglo de Oro, Burgos-La Rioja, 2002.

Centeno Carnero, Gloria, Monasterio de Santa María de Jesús, Sevilla, 1996.

Checa Cremades, Fernando, Tiziano y la monarquía hispánica, Madrid, 1994.

Checa, Fernando y Morán, Miguel, El coleccionismo en España. De la cámara de las maravillas a la galería de pinturas, Madrid, 1985.

Cruz Isidoro, Fernando, "El convento de Santo Domingo de Sanlúcar de Barrameda: patronazgo de los Guzmanes, proceso constructivo y patrimonio artístico (1528-1605)", en Laboratorio de Arte, n. ${ }^{\circ}$ 23, 2011.

De la Torre Fazio, Julia, El retrato español en miniatura bajo los reinados de Felipe II y Felipe III, Tesis doctoral, Universidad de Málaga, 2009.

De Mayoralgo y Lodo, J. M., El Linaje sevillano de los Villasis. Anales de la Real Academia Matritense de Heráldica y Genealogía, vol. IV, Madrid, 1996-1997.

Falomir Faus, Miguel, "De la cámara a la galería. Usos y funciones del retrato en la Corte de Felipe II", en AA.VV., en Doña María de Portugal. Princesa de Parma (1565-1577) e suo tempo, Oporto, 1999.

Falomir Faus, Miguel, "Felipe II ofreciendo al cielo al infante don Fernando", en Tiziano, cat. exp., Madrid, 2003.

59 PÉrez SÁNCHEZ, 1976: 155.

${ }^{60}$ Las últimas mandas del codicilo reafirman aspectos ya expuestos en el testamento. No obstante, Jerónimo revocó la cláusula alusiva a la liberación de su esclavo, que pasaba a quedar dentro del montante de sus bienes. Dejó a su esposa al cuidado de todo lo dispuesto y nombró a tres nuevos albaceas: Cristóbal de Salcedo, Diego de Velasco y Julio Manfredo.

${ }^{61}$ Otorgó este poder a Luis de Medina Rufino. AHPSe. SPNSe.: Legajo 6813, oficio 11, Libro 2. ${ }^{\circ}$ de 1592, fol. 980 recto-vuelto.

Arch. esp. arte, LXXXVII, 345, ENERO-MARZO 2014, 15-28

ISSN: 0004-0428, eISSN: 1988-8511, doi: 10.3989/aearte.2014.02 
Falomir Faus, Miguel, “Tiziano. Alegoría, política, religión”, en Álvarez Lopera (coord.), Tiziano y el legado veneciano, Barcelona, 2005.

Fernández Luzón, Antonio, La Universidad de Barcelona en el siglo XVI, Barcelona, 2005.

García Fuentes, Lutgardo, Los peruleros y el comercio de Sevilla con las Indias, 1580-1630, Sevilla, 1997.

Guill Ortega, Miguel Ángel, “Alonso Coloma (c. 1556-1606). Poesía, nobleza y religión”, en Revista del Vinalopó, n. ${ }^{\circ} 13,2010$.

Jordán de Urriés y Azara, José, Biografía y estudio crítico de Jáuregui, Madrid, 1899.

Kusche, María, "La antigua galería de retratos de El Pardo: su importancia para la obra de Tiziano, Moro, Sánchez Coello y Sofonisba Anguissola y su significado para su fundador, Felipe II", en Archivo Español de Arte, n. $^{\circ} 257,1992$.

Kusche, María, Retratos y retratadores: Alonso Sánchez Coello y sus competidores Sofonisba Anguissola, Jorge de la Rúa y Rolán Moys, Madrid, 2003.

López Jiménez, José Carlos, "Correspondencia pictórica valenciano-murciana. Siglos XVI y XVII", en Archivo de Arte Valenciano, . $^{\circ}$ 37, 1966.

López Jiménez, José Carlos, "Pinturas del siglo XVI al XVII y unas esculturas medievales en la Diócesis de Orihuela y Cartagena", en Archivo de Arte Valenciano, n. ${ }^{\circ}$ 45, 1974.

López Martínez, Celestino, Arquitectos, escultores y pintores vecinos de Sevilla, Sevilla, 1928a.

López Martínez, Celestino, Retablos y esculturas de traza sevillana, Sevilla, $1928 b$.

Malo Lara, Lina, El retablo pictórico en la Sevilla del Siglo XVII, Tesis doctoral (inédita), Universidad de Sevilla, 2006.

Mulcahy, Rosemarie, "En la sombra de Alonso Sánchez Coello: la búsqueda por Jerónimo Sánchez", Archivo Español de Arte, n. ${ }^{\circ}$ 63, 1990.

Muro Orejón, Antonio, Pintores y Doradores, en Documentos para la Historia del Arte en Andalucia, T. VIII, Sevilla, 1935.

Pacheco, Francisco, El Arte de la Pintura: su antigüedad y grandeza, Sevilla, 1649, Ed. B. Bassegoda i Hugas, Madrid, 2001.

Palomero Páramo, Jesús M., El retablo sevillano del Renacimiento: análisis y evolución (1560-1629), Sevi1la, 1983.

Pérez Sánchez, Alfonso E., "Presencia de Tiziano en la España del Siglo de Oro", Goya, n. ${ }^{\circ}$ 135, 1976.

Redin Micheus, Gonzalo: Pedro Rubiales, Gaspar Becerra y otros pintores españoles en Roma 1527-1600, Madrid, 2007.

Salas Almela, Luis, Medina Sidonia: el poder de la aristocracia (1580-1670), Madrid, 2008.

Salort Pons, Salvador, "Las relaciones artísticas entre Italia y Sevilla durante el primer tercio del siglo XVII", en De Herrera a Velázquez: el primer naturalismo en Sevilla, (ed. Pérez Sánchez, Alfonso E. y Navarrete Prieto, B.), cat. exp., 2005.

Santos Márquez, Antonio J., "Francisco de Valderrama, verdadero autor de las mazas del Ayuntamiento de Sevilla", Archivo Español de Arte, n. ${ }^{\circ} 326,2009$.

Seguí Cantos, José, "El memorial de D. Alonso Coloma en su visita a la Universidad de Valencia (15981599)", Hispania: Revista española de historia, vol. 52, n. ${ }^{\circ}$ 180, 1992.

Serrera Contreras, Juan M., “Alonso Sánchez Coello y la mecánica del retrato de Corte”, en Alonso Sánchez Coello y el retrato en la Corte de Felipe II, cat. exp., Madrid, 1990.

Serrera Contreras, Juan M., "El eco de El Escorial. Las tumbas de los XII Condes de Niebla", en Felipe II y el arte de su tiempo, Madrid, 1998.

Torre Revello, José, "Lecturas indianas (siglos XVI-XVIII)", en Thesaurus, Boletín del Instituto Caro y Cuervo, T. XVII, n. ${ }^{\circ}$ 1, enero-abril, 1962.

Valdivieso González, Enrique, Juan de Roelas, Sevilla, 1978.

Valdivieso González, Enrique, Historia de la pintura sevillana. Sevilla, 1986.

Valdivieso González, Enrique, Pintura barroca sevillana, Sevilla, 2003.

Valdivieso González, Enrique (comisario), Juan de Roelas (h. 1570-1625), cat. exp., Sevilla, 2008.

Fecha de recepción: 15-II-2013

Fecha de aceptación: 12-VI-2013

Arch. esp. arte, LXXXVII, 345, ENERO-MARZO 2014, 15-28 ISSN: 0004-0428, eISSN: 1988-8511, doi: 10.3989/aearte.2014.02 